\title{
Does Migrants are More Vulnerable to Substance Abuse? A Study of Mumbai Slum Migrants
}

\author{
Masthanaiah Tadapatri ${ }^{1}$, Karunakara Rao Muppasani ${ }^{2}$ \\ ${ }^{1,2}$ Research Scholar, Department of Geography, Sri Krishnadevarya University, Anantapur, Andhra Pradesh, India
}

\begin{abstract}
The epidemic of substance abuse has assumed alarming dimensions in India. Migrant people abuse substances such as drugs, alcohol, and tobacco for varied and complicated reasons, but it is clear that our society pays a significant cost. The toll for this abuse can be seen, in our hospitals and emergency departments, through direct damage to health by substance abuse and its link to physical trauma. The main aim is an attempt has been made to understand the migrant's substance use behaviour by their background characteristics. Consumption of alcohol, both smoke and smokeless forms of tobacco use, who are regularly with high frequency in day taking alcohol and regular use tobacco forms of among migrants has been captured in this study. Present study is based on the quantitative interviews of 300 male migrants with each 100 respondents of never married, married but not staying with wife and staying with wife, those who are migrated from Andhra Pradesh to Bhiwandi slum areas of Mumbai. The results of logistic regression reveal that alcohol consumption is associated with moderate/high wealth index, marital status and job stress. It seems the migrants who belong to high wealth index (AOR: 9.14, 95\% CI: 76-47.28), moderate wealth index (AOR: 7.56, 95\% CI: 2.15-26.50) are more likely to consume alcohol that the migrants belonging to low wealth index. Migrants who are staying with wife, migrants who not staying with wife are more likely to consume alcohol than the unmarried migrants
\end{abstract}

Keywords: Andhra Pradesh, migrant workers, background characteristics, substance abuse.

\section{Introduction}

Migrants are faced with multiple socioeconomic, environmental and cultural factors making that increase vulnerability for substance abuse and related problems. Economic insecurity, high levels of poverty that force families to live in deprived neighborhoods, discrimination, experiences of inequality, levels of acculturation and a pervasive sense of powerlessness are among the many factors that increase the experience of stress. The epidemic of substance abuse has assumed alarming dimensions in India. Changing cultural values, increasing economic stress and dwindling supportive bonds are leading to initiation into substance use. According to the World Health Organization (WHO), substance abuse is persistent or sporadic drug use is inconsistent with or unrelated to acceptable medical practice. Substance abuse can simply be defined as a pattern of harmful use of any substance for mood-altering purposes. Medline's medical encyclopedia defines drug abuse as "the use of illicit drugs or the abuse of prescription or over-thecounter drugs for purposes other than those for which they are indicated or in a manner or in quantities other than directed. People abuse substances such as drugs, alcohol, and tobacco for varied and complicated reasons, but it is clear that our society pays a significant cost. The toll for this abuse can be seen, in our hospitals and emergency departments, through direct damage to health by substance abuse and its link to physical trauma.

Substance abuse is a major source of morbidity and mortality in India. Tobacco related deaths are increasing in India, and account for approximately a sixth of the world's tobacco related deaths. Workers in this industry need to do heavy physical work while living in shabby environment. The unhygienic situation, working pattern, absence of any recreational activity and company of friends force them to indulge in various abuse activities. Substance abuse is influenced by a variety of factors including individual attitudes \& beliefs, social norms, easy affordability, acceptability, availability, lesser cost and advertising campaigns. There are many misconceptions regarding the tobacco and alcohol, that it helps increase concentration, suppresses appetite, reduces anxiety and tension, causes skeletal muscle relaxation and induces feeling of pleasure.

Substance use and abuse can result when attempting to cope with these specific stressors in addition to the daily challenges that they confront. Substance abuse has a substantial and reciprocal impact upon families. Substance abuse by family members can have a substantial negative effect on the financial viability of caregivers. Substanceabusing caregivers may spend money allocated for food or clothing for children. Substance abusers may divert money from rent or mortgages to buy substances. Noncustodial parents who abuse alcohol are less likely to provide financial support for their children (Dion et al. 1997). Additionally, families are often unwitting accomplices to their relative's substance abuse as the substance use is often financed by immediate family members (Gearon et al. 2001).

\section{Literature Review}

Studies have shown that the environment where an individual lives can have a great impact on the consumption of substances as a result of local customs, traditions, and norms of the area (Calderón, Campillo, \& Suárez, 1981). For many people, migration and resettlement result in social isolation and loneliness. This is especially so when people move alone. The relief found in temporary friendships and supportive social environments at ethnic bars often heightens dependency on alcohol and other substances, and alcohol abuse is a frequent problem among single migrants. The fact that migrants are often qualified for only low skilled jobs also means they are often confined to high-risk and irregular occupational settings. The fact that they come into them with little previous experience and receive little training and safety support means that they are often exposed to health problems and accidents associated with 


\section{International Journal of Science and Research (IJSR) \\ ISSN (Online): 2319-7064 \\ Index Copernicus Value (2013): 6.14 | Impact Factor (2015): 6.391}

low-skilled jobs (Manuel Carballo and etal 2001). Epidemiological studies have found that among immigrants in general and Mexican migrant's in particular longer duration of residence in the United States is associated with higher risk for substance use disorders (Guilherme Borges eatl. 2007). Tobacco, alcohol, and illicit substance use continue to result in substantial morbidity and mortality and significant societal economic costs despite considerable efforts to minimize use of licit substances and prevent use of illicit substances. Each year, more than 400,000 Americans die from cigarette smoking, and one in every five deaths in the United States is believed to be smoking related (TIPS2001). There are many misconceptions regarding the tobacco and alcohol, that it helps increase concentration, suppresses appetite, reduces anxiety and tension, causes skeletal muscle relaxation and induces feeling of pleasure (TIPS-2001). Migration from different states to other states in India has now become so rampant that its impact is felt in every aspect of life. Very few studies have explored the problems of construction workers even though they are more susceptible to various myriad of occupational hazards. Majority of employees in the construction sector are aged between 15 and 45, live in single sex quarters, and migrate to their place of work. Hence, alcohol abuse or other risk- taking behaviour is quite common in any area of this sector (Cook. RF and eatl. 2004).

\section{Study Area}

Bhiwandi is a city, in the district of Thane, in the western state of Maharashtra, in India, located $20 \mathrm{~km}$ to the northeast of Mumbai and $15 \mathrm{~km}$ to the north-east of Thane city. The city is considered a part of the Greater Mumbai Metropolitan Agglomeration, along with Navi Mumbai. The exact location of Bhiwandi is $19.296664^{\circ} \mathrm{N}$ latitude and $73.063121^{\circ} \mathrm{E}$ longitude. It is one of the most industrialized cities of India, with one of the fastest population growth rate due to immigration from various parts of the country. The Power loom industry is the main reason for huge number of floating population. Migrant workers especially from Uttar Pradesh, Bihar, Andhra Pradesh, Orissa, Gujarat and Rajasthan came in droves to find work at these centres. Bhiwandi became the 2nd largest power loom centre in the country after Surat city power loom. Most of the Power looms are operated in residential area. In a congested area the power looms are operated and these create a health and sanitation issue of power loom operators.

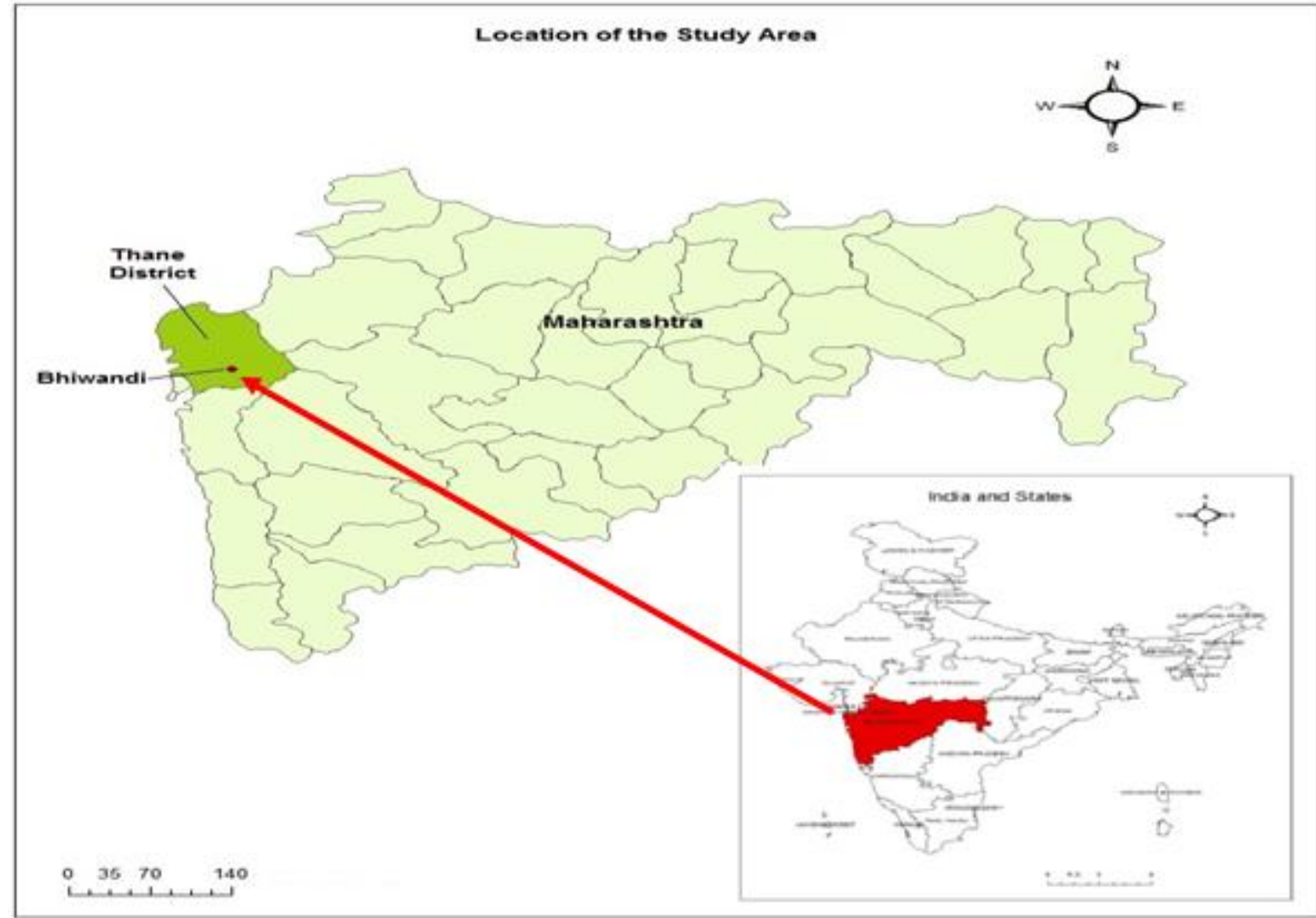

Figure 1: Location of the study area

\section{Objective}

The main aim is an attempt has been made to understand the migrant's substance use behaviour by their background characteristics. Consumption of alcohol, both smoke and smokeless forms of tobacco use, who are regularly with high frequency in day taking alcohol and regular use tobacco forms of among migrants has been captured in this study.
Types of tobacco: Smokeless forms of tobacco use: Paan (betel quid) with tobacco, Paan masala with tobacco, Tobacco, areca nut and slaked lime preparations, Mawa, Khaini, chewing tobacco, snus, and gutkha.

Smoked forms of tobacco use: Bidis, Cigarettes, Cigars, Cheroots, Chuttas, Dhumti, Pipe, Hooklis, Chillum, and Hookah. 


\section{International Journal of Science and Research (IJSR) \\ ISSN (Online): 2319-7064}

Index Copernicus Value (2013): 6.14 | Impact Factor (2015): 6.391

Tobacco products for application: Mishri, Gul, Laldantmanjan, Gudhaku, Creamy Snuff, Tobacco water, Nicotine chewing gum. Types of alcohol: Foreign liquor, Country liquor, Hathbatti / Tadimadi and other liquor has been captured.

\section{Data and Methodology}

Primary data has been used for this study. Using mix method approach data were collected through structured questionnaire from Bhivandi slum areas in Mumbai, in year 2012. Total 300 male migrant workers who migrated from Andhra Pradesh to Bhiwandi sulm areas of Mumbai were interviewed. The data has been collected equally (100) from each of the three categories, viz. never married, married but not living with their wives and living with their wives. Descriptive statistics, bivariate, uni-variate analysis has been used for the present study by using Statistical Package for Social Sciences (SPSS). For measuring the intensity of substance use of migrant behaviour, both wealth Index of at work place and native place wealth index of substance use, exposure of mass media, marital status, job stress and life satisfaction has been constructed. Independent variables are age, education, caste, religion, marital status, economic and living conditions of native and destination place.

\section{Findings}

\section{Substance Use V.S. Selected Characteristics of Migrants:}

\subsection{Regular tobacco use by migrants}

Table no. 1 shows the percent distribution of migrants by regular tobacco use according to the selected background characteristics. Migrants of younger age groups, i.e below 25 years $(46 \%)$ seems to have less regular tobacco consumption than the migrants of 26-35 years (55\%) and migrants of 36 years and above (55\%). Vast majority (70\%) of migrants who has 1-5 years of schooling reported regular use of tobacco whereas 33 percent of those whose education was $10+$ years, 52 percent of 6-9 years of education, and 49 percent of uneducated respondents reported the regular use of tobacco. Among the migrants belonging to SC/ST communities, 56 percent reported regular tobacco use which is slightly higher than that of the migrants of non SC/ST communities (53\%). Looking by wealth index, 55 percent of migrants who belong to low wealth quintile and slightly more than that $(57 \%)$ of migrants who belong to moderate wealth quintile reported regular use. Non exposures to electronic media $(63 \%)$ reported more than their counterpart $(46 \%)$. Nearly half (49\%) of the respondents those who are exposed to film media and 55 percent of migrants who are not exposed to film media reported regular use of tobacco. Lower proportion of migrants who had exposures to print media (43\%) rather than the migrants who were not exposed to print media $(65 \%)$ reported regular tobacco use. Three fifths $(60 \%)$ of respondents belonging to high native wealth quintile reported regular use of tobacco and slightly less $(59 \%)$ in case of respondents belonging to low wealth quintile and only 41 percent of respondents belonging to moderate wealth quintile reported regular use of tobacco. Almost three fifths of $(59 \%)$ migrants whose migration duration is less than 4 years, half of $(50 \%)$ the migrants whose migration duration is 4 to 7 years and 54 percent of those whose migration duration is above seven years reported regular use of tobacco.

More than half of migrants $(52 \%)$ those who have low negative emotions and 64 percent of respondents having high negative emotions reported regular use of tobacco. Half $(50 \%)$ of the migrants belonging to less job stress levels and 64 percent of the respondents of whose job stress levels were high reported regular use of tobacco. Similarly, 55 percent of migrants with less satisfaction level of life and 53 percent high satisfaction levels of life reported of using tobacco regularly.

\subsection{Smoke regularly by migrants}

Table no.1 presents that percent distribution of migrants of those who smoke regularly according to their selected background characteristics. The data shows that migrants married and not staying with wife (45\%) smoke regularly, higher than the migrants married and staying with wife $(33 \%)$ and never married migrants $(29 \%)$. Nearly one third $(33 \%)$ of uneducated respondents reported regular smoking while, 40 percent migrants who has 1-5 years schooling, 41 percent of migrants with 6-9 years schooling and 31 percent migrants who have more than 10 years of schooling reported regular smoking. Looking at the wealth index, 39 percent of migrants belonging to low wealth quintile, 35 percent of moderate quintile at current place and $40 \%$ of the respondents who belong to high wealth quintile reported regular smoking. Non exposurers to electronic media (35\%) reported less than its counterparts (40\%). Two fifth (40\%) of the respondents those who are exposed to film media and 37 percent migrants not exposed to film media reported regular smoking. Almost 38 percent migrants who have exposures to print media and 36 percent of the respondents who are not exposed to print media reported regular smoking. More than two fifth $(43 \%)$ migrants of low native wealth quintile and slightly more than that (46 percent) of moderate wealth quintile and less than quarter (23\%) of migrants of high native wealth quintile reported regular smoking.

By duration of migration, 45 percent migrants whose migration duration is less than 4 years, 43 percent migrants whose migration duration is 4 to 7 years and 29 percent of those whose migration duration is above seven years reported regular smoking. Thirty seven percent of the migrants of low negative emotion scale and 40 percent of high negative emotion scale reported regular smoking. One third $(33 \%)$ migrants of less job stress levels and 39 percent migrants of high job stress levels reported regular smoking. Almost same proportion of migrants of low and high $(37 \%$ .vs. 38\%) satisfaction levels of life reported to smoke regularly.

\subsection{Regular Alcohol consumption by migrants}

Table no.1 reveals percent distribution of regular alcohol consumption by their selected background characteristics. Alcohol consumption is one of the substance abuse among migrants which affect economic and health status. Several studies have already quoted that, majority of the migrants often tend to consume alcohol to get rid of their work related 


\section{International Journal of Science and Research (IJSR) \\ ISSN (Online): 2319-7064 \\ Index Copernicus Value (2013): 6.14 | Impact Factor (2015): 6.391}

stress. More than one sixth (16\%) of the migrants aged 25 and below reported that they consume alcohol regularly while 27 percent of age group of 26 to 35 years and 42 percent of age group 36 years and above reported of having consumed alcohol regularly. It clearly shows that alcohol consumption is high among the older age migrants. Looking at the educational level, 44 percent of the migrants with 1-5 years of schooling consume alcohol followed by the migrants with no schooling (37\%), 6-9 years schooling $(24 \%)$ and 10 and above years of schooling (7\%). One quarter $(25 \%)$ of migrants belonging to SC/ST communities and 30 percent of non-SC/ST communities reported regular consumption of alcohol. Fifteen percent of migrants belonging to low wealth quintile, 38 percent belong to moderate wealth quintile category and nearly one quarter (24\%) of high wealth quintile category reported regular alcohol consumption. Higher proportion of migrant group having no exposures to electronic media (39\%) reported regular consumption of alcohol than their counterparts (22\%). With respect to film media, migrants who are not exposed $(30 \%)$ reported higher proportion of alcohol consumers rather than the migrants who are exposed to film media (26\%). Similarity can be observed in case of migrants' exposure to print media, where 19 percent of exposures and 41 percent of non exposures reported alcohol consumption. Almost equal percent of migrants belonging to low native wealth quintile and migrants belonging to moderate native wealth quintile reported regular alcohol consumption( $28.3 \%, 28.6 \%)$, whereas 31percent of the respondents who belong to high native wealth quintile reported regular consumption of alcohol. Thirty five percent of male migrants whose migration duration is less than 4 years, 24 percent migrants whose migration duration is 4 years to less than 7 and 31percent of those whose migration duration is above seven years reported regular alcohol consumption showing no definite relationship with duration of migration. And also studies have shown that the environment where an individual lives can have a great impact on the consumption of substances as a result of local customs, traditions, and norms of the area (Calderón, Campillo, \& Suárez, 1981).

Migrants with high negative emotion scale (37\%) reported to consume alcohol, higher than the migrants of less negative emotion scale $(28 \%)$. Almost one sixth of the migrants $(16 \%)$ of less job stress levels and 34 percent of the respondents of those high job stress levels were reported regular alcohol consumption. One third (33\%) of respondents those who have less satisfaction levels of life and 26 percent of respondents those who have high satisfaction levels of life reported of consuming alcohol regularly. Higher proportions migrants with high negative emotion, high job stress, low life satisfaction scales are consuming alcohol regularly.

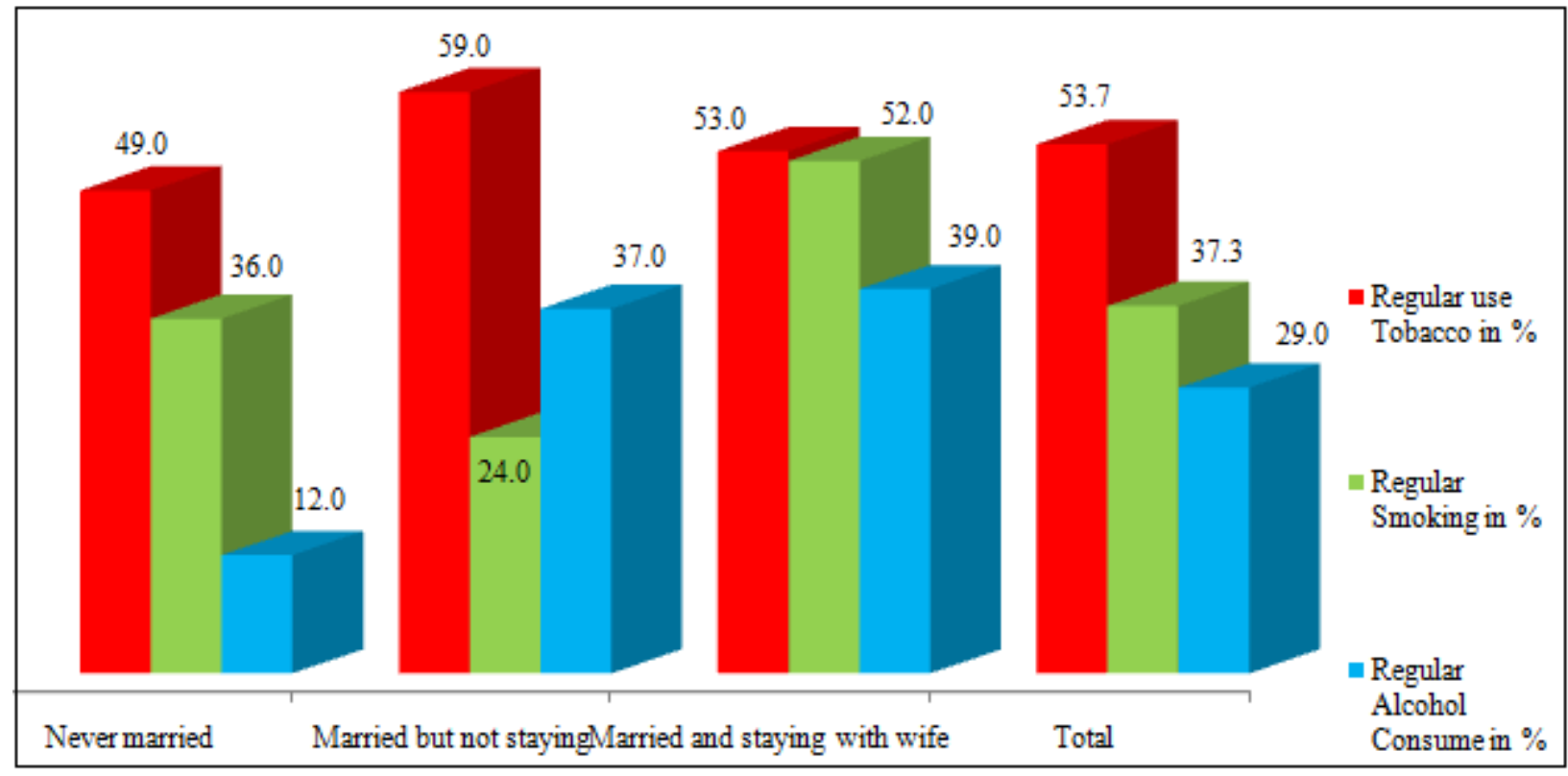

Figure 2: Migrants who Consuming regularly Tobacco, Smoking and alcohol by their marital status.

Figure no.2 demonstrates percent distribution of migrants by regular tobacco use, smoking and regular alcohol consumption according to their marital status. Fifty nine percent of married and not staying with wife migrants are highly consuming tobacco regularly compare to their counterparts. Followed by unmarried migrants 49 percent, married staying with wife migrants 53 percent consuming tobacco regularly. Nearly a quarter $(24 \%)$ of married migrants who are not staying with wife, 52 percent married migrants staying with wife and 36 percent unmarried male migrants reported that they smoke regularly. Migrants alcohol consumption by their marital status. Never married male migrants (12\%) reported less of regular alcohol consumption than their counterparts; migrants married and not staying with wife $(37 \%)$ and migrants married and staying with wife $(39 \%)$.

Association between Chewing Tobacco and Selected Covariates: Table no 2 presents regression analysis shows that, Chewing tobacco seems to be high among the migrants having schooling 1-5 years (AOR: 6.82, 95\% CI: $1.93-$ 24.08) than migrants who has no schooling. Almost 6.8 times they are more likely to have habit of chewing tobacco. Looking at the influence of media, film media is strongly 


\section{International Journal of Science and Research (IJSR) \\ ISSN (Online): 2319-7064}

Index Copernicus Value (2013): 6.14 | Impact Factor (2015): 6.391

associated with chewing tobacco, while electronic media and print media seem to have negative association with chewing tobacco. The migrants who have exposure to film media are 2.8 times more likely to have habit of chewing tobacco.

Association between regular smoking and Selected Covariates: Table no 2 presents regression analysis shows that, smoking among migrants is associated with age, job stress and life satisfaction. Migrants belonging to age group 36 years and above (AOR: $4.47,95 \%$ CI: $1.21-16.45$ ) are 4.5 times more likely to have smoking habit than the migrants of below 26 years. Similarly, migrants who has high score in job stress scale (AOR: 7.70, 95\% CI: 2.18-27.16) and migrants who has high score in life satisfaction (AOR: 4.07, 95\% CI: $1.45-11.35$ ) are more likely to smoke than the less scored migrants. It clearly shows that, habit of smoking is not only related to stress but also to have fun and enjoyment as the migrants who are satisfied with life are also 4 times more likely to have habit of smoking.

Association between Alcohol consumption and Selected Covariates: Table no 2 present's regression analysis shows that, Alcohol consumption is associated with moderate/high wealth index, marital status and job stress. It seems the migrants who belong to high wealth index (AOR: 9.14, 95\%CI: 1.76-47.28), moderate wealth index (AOR: 7.56, 95\% CI: 2.15-26.50) are more likely to consume alcohol than the migrants belonging to low wealth index. Migrants who are married and staying with wife (AOR: $4.08,95 \% \mathrm{CI}$ : 1.22-13.57), and migrants who are married and not staying with wife (AOR: 3.63, 95\% CI: 1.10-11.88) are more likely to consume alcohol than the unmarried migrants. Migrants who has high score in job stress (AOR: 4.34, 95\% CI: $1.27-$ 14.84) are more likely to consume alcohol than the migrants who has less job stress. The regression analysis also reveals that, the alcohol consumption among the migrants who had exposure to electronic media (AOR: 0.38 , 95\% CI: $0.15-$ 0.94 ) and print media (AOR: $0.28,95 \%$ CI: 0.11-0.72) are less likely to consume alcohol than the migrants who do not have exposure. However, film media does not show any significant role in promoting alcohol consumption among migrants, like chewing tobacco.

\section{Conclusions}

Several studies pointed out earlier, migrant populations have a greater risk for poor health in generally. This is due to the impact of socio-cultural patterns of the migrant situation on health, their economic transitions, reduced availability and accessibility of health services. Social behaviour of migrants also influences their consumption of substance abuse pattern. Overall the study explores certain socio behavioral traits of migrants that are much influenced by their consumption of tobacco and alcohol, regular smokings are reported irrespective of their marital status and it also observed that these behavioural traits are not much related to their marital status. More than half of migrants reported regular tobacco use (54\%), Followed by regular smoking 37 percent and alcohol consumption is 29 percent.

However, there emerged some interesting patters, in the regression analysis, that, chewing tobacco seems to be high among the migrants having schooling 1-5 years than migrants who has no schooling. Almost 6.8 times they are more likely to have habit of chewing tobacco. Looking at the influence of media, film media is strongly associated with chewing tobacco, while electronic media and print media seem to have negative association with chewing tobacco. The migrants who have exposure to film media are 2.8 times more likely to have habit chewing tobacco. The regression analysis shows that, smoking among migrants is associated with age, job stress and life satisfaction. Migrants belonging to age group 36 years and above are 4.5 times more likely to have smoking than the migrants of below 26 years.

\section{Policy Recommends}

An efforts should be made by government towards counseling on reduce substance abuse and Strengthening IEC components through peer education and media and IEC activities for prevention of the national tobacco/substance control program are necessary to address this problem. Success in such efforts will require the contribution of teachers, parents and nongovernment organizations.

\section{References}

[1] UNAIDS Report in the Global AIDS Epidemic: 4th Global Report. Geneva: UNAIDS/WHO; 2004.

[2] WHO. Techn. Res. Ser. No.886: 1999. p. 48.

[3] https://en.wikipedia.org/wiki/Substance_abuse:

[4] Substance Abuse and Addiction Health Center; http://www.webmd.com/mental-

health/addiction/substance-abuse; Accessed 280116 TIME 14:46.

[5] John RM, Rao RK, Rao MG, Moore J, Deshpande RS, Sengupta $\mathbf{J}$ et al. The Economics of Tobacco and Tobacco Taxation in India. Paris: International Union against Tuberculosis and Lung Disease [Internet]. Available

from:

http://tobaccofreecenter.org/files/pdfs/en/

India_tobacco_taxes_report_en.pdf [Accessed on 2016 January 20].

[6] 5. Cook RF, Hersch RK, Back AS, McPherson TL. The Prevention of Substance Abuse among Construction Workers: A Field Test of a Social-Cognitive Program. The Journal of Primary Prevention 2010; 25(3): 337-57.

[7] Connecting Across Culture: http://cac.hhd.org/pdf/FAQ3_RWJ.pdf, [Accessed on 2016 January $28^{\mathrm{th}}$ time: 15:07].

[8] http://www.encyclopedia.com/topic/Substance_abuse.as px.

[9] Dion, m.; braver, s.; wolchick, s.; and sandler, i. (1997)."Alcohol abuse and psychopathic deviance in non-custodial parents as predictors of child-support payment and visitation." american journal of orthopsychiatry 67(1):70-79.

[10]Dearon, j. s.; bellack, a. s.; rachbeisel, j.; and dixon, 1.(2001). "drug-use behavior and correlates in people with schizophrenia." addictive behaviors 26(1):51-61.

[11]Flavio Francisco Marsiglia eatl, (2011), Migration Intentions and Illicit Substance Use among Youth in Central Mexico; Substance Use Misuse; 46(13): 16191627. doi:10.3109/10826084.2011.590957. 


\section{International Journal of Science and Research (IJSR) \\ ISSN (Online): 2319-7064 \\ Index Copernicus Value (2013): 6.14 | Impact Factor (2015): 6.391}

[12] Manuel Carballo and Aditi Nerurkar Migration, Refugees, and Health Risks; Emerging Infectious Diseases; Vol. 7, No. 3 Supplement, June 2001.

[13] Guilherme Borges eatl, (2007) The Effect of Migration to the United States on Substance Use Disorders Among Returned Mexican Migrants and Families of Migrants, October 2007, Vol 97, No. 10.

[14] National Center for Disease Prevention and Health Promotion. Tobacco information and prevention source (TIPS). June 2001. http://www.cdc.gov/tobacco/research_data/ health consequences/mortali.htm.
[15] World Health Organization. Tobacco increases the poverty of individuals and families. World Health Organization $2004 \quad$ Available from:http:/www.who.int/tobacco/communications/ events/wntd/2004/en/factsindividuals_en.pdf. [Accessed on 2016 January 23].

[16] Cook RF, Hersch RK, Back AS, McPherson TL. The Prevention of Substance Abuse among Construction Workers: A Field Test of a Social-Cognitive Program. The Journal of Primary Prevention 2010; 25(3): 337-57

Table 1: Migrants reported who using regularly Tobacco, smoking and consuming alcohol.

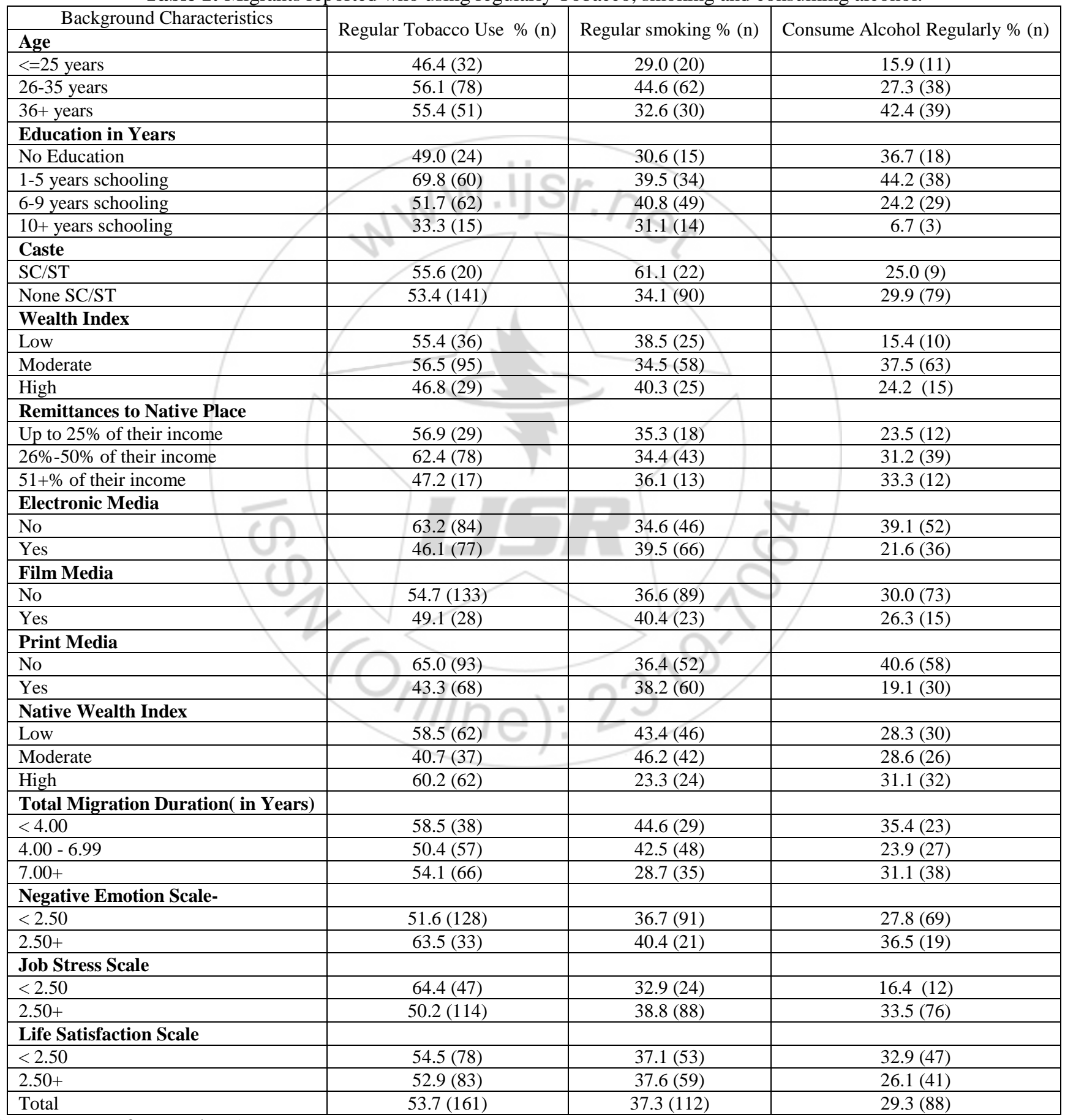

(Note: $\mathrm{n}=$ no. of respondents) 


\section{International Journal of Science and Research (IJSR) \\ ISSN (Online): 2319-7064 \\ Index Copernicus Value (2013): 6.14 | Impact Factor (2015): 6.391}

Table 2: Associations between substance abuse (chewing tobacco, smoking and alcohol) and Selected Covariates

\begin{tabular}{|c|c|c|c|c|c|c|}
\hline \multirow{2}{*}{$\begin{array}{c}\text { Background characteristics } \\
\text { Age }\end{array}$} & \multicolumn{2}{|c|}{ Chewing tobacco } & \multicolumn{2}{|c|}{ Regular smoking } & \multicolumn{2}{|c|}{ Alcohol consumption } \\
\hline & $\operatorname{Exp}(b)$ & $\begin{array}{l}\text { 95\% CI (MIN- } \\
\text { MAX) }\end{array}$ & $\operatorname{Exp}(b)$ & $\begin{array}{l}\text { 95\% CI (MIN- } \\
\text { MAX) }\end{array}$ & $\operatorname{Exp}(b)$ & $\begin{array}{l}\text { 95\% CI (MIN- } \\
\text { MAX) }\end{array}$ \\
\hline \multicolumn{7}{|l|}{$<=25$ years } \\
\hline $26-35$ years & 1.51 & $0.59-3.84$ & 3.67 & $1.28-10.51$ & 1.38 & $0.43-4.40$ \\
\hline $36+$ years & 1.04 & $0.33-3.27$ & 4.47 & $1.21-16.45$ & 1.08 & $0.29-4.02$ \\
\hline \multicolumn{7}{|l|}{ Education } \\
\hline \multicolumn{7}{|l|}{ No Education } \\
\hline $1-5$ years schooling & 6.82 & $1.93-24.08$ & 0.72 & $0.19-2.67$ & 3.44 & $0.93-12.72$ \\
\hline 6-9 years schooling & 3.40 & $0.96-12.02$ & 0.38 & $0.09-1.59$ & 2.42 & $0.63-9.26$ \\
\hline 10+ years schooling & 4.24 & $0.88-20.38$ & 0.49 & $0.08-3.06$ & 0.73 & $0.09-5.92$ \\
\hline \multicolumn{7}{|l|}{ Caste } \\
\hline \multicolumn{7}{|l|}{$\mathrm{SC} / \mathrm{ST}$} \\
\hline Non- SC/ST & 1.37 & $0.40-4.61$ & 0.08 & $0.02-0.29$ & 0.62 & $0.15-2.52$ \\
\hline \multicolumn{7}{|l|}{ Wealth Index (after migration) } \\
\hline \multicolumn{7}{|l|}{ Low } \\
\hline Moderate & 0.44 & $0.17-1.13$ & 1.15 & $0.44-3.04$ & 7.56 & $2.15-26.50$ \\
\hline High & 0.82 & $0.22-3.05$ & 1.25 & $0.29-5.32$ & 9.14 & $1.76-47.28$ \\
\hline \multicolumn{7}{|l|}{ Remittance } \\
\hline \multicolumn{7}{|l|}{$\begin{array}{l}\text { Remittance Up to } 25 \% \text { of their } \\
\text { income }\end{array}$} \\
\hline $26 \%-50 \%$ of their income & 1.54 & $0.68-3.52$ & 1.03 & $0.42-2.52$ & 1.18 & $0.45-3.08$ \\
\hline $51+\%$ of their income & 0.84 & $0.28-2.49$ & 0.98 & $0.28-3.48$ & 1.39 & $0.39-4.91$ \\
\hline \multicolumn{7}{|l|}{ Electronic Media } \\
\hline \multicolumn{7}{|l|}{ No } \\
\hline Yes & 0.39 & $0.17-0.87$ & 2.02 & $0.82-4.98$ & 0.38 & $0.15-0.94$ \\
\hline \multicolumn{7}{|l|}{ Film media } \\
\hline No & 7 & 7 & & s & & \\
\hline Yes & 2.75 & $1.04-7.31$ & 1.81 & $0.60-5.42$ & 1.67 & $0.52-5.41$ \\
\hline Print media & 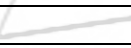 & . & & +1 & & \\
\hline No & & + & 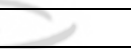 & & & \\
\hline Yes & 0.18 & $0.07-0.47$ & 1.04 & $0.39-2.71$ & 0.28 & $0.11-0.72$ \\
\hline \multicolumn{7}{|l|}{ Wealth index (before migration) } \\
\hline \multicolumn{7}{|l|}{ Low } \\
\hline Moderate & 0.64 & $0.24-1.67$ & 1.15 & $0.41-3.17$ & 2.31 & $0.78-6.88$ \\
\hline 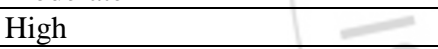 & 1.19 & $0.49-2.93$ & 0.07 & $0.02-0.23$ & 1.53 & $0.57-4.10$ \\
\hline \multicolumn{7}{|l|}{ Marital status } \\
\hline Not married & & 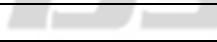 & $2+1$ & 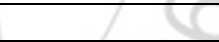 & 7 & \\
\hline Married but wife not stay with me & 1.75 & $0.64-4.77$ & 0.12 & $0.03-0.42$ & 3.63 & $1.10-11.88$ \\
\hline Wife stay with me & 2.16 & $0.69-6.72$ & 0.88 & $0.29-2.69$ & 4.08 & $1.22-13.57$ \\
\hline Negative emotion Scale & & $Y_{1}$ & $>$ & $V$ & & \\
\hline$<2.50$ & 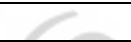 & 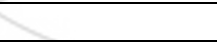 & 3 & $\mathrm{C}=$ & & \\
\hline $2.50+$ & 2.62 & $0.94-7.27$ & 0.80 & $0.27-2.37$ & 0.68 & $0.23-1.98$ \\
\hline Job stress Scale & 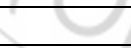 & 210 & $\mathrm{O}^{\prime \prime}$ & 2 & & \\
\hline$<2.50$ & $>$ & 110 & 18 & 2 & & \\
\hline $2.50+$ & 0.39 & $0.15-1.01$ & 7.70 & $2.18-27.16$ & 4.34 & $1.27-14.84$ \\
\hline Life satisfaction Scale & & 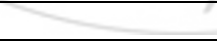 & 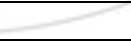 & & & \\
\hline$<2.50 "$ & & & & & & \\
\hline $2.50+$ & 1.24 & $0.52-2.95$ & 4.07 & $1.45-11.35$ & 2.25 & $0.82-6.18$ \\
\hline
\end{tabular}

Volume 5 Issue 5, May 2016 www.ijsr.net 